Original Article

\title{
Intubating Conditions with three different doses of Rocuronium in surgery of cancer patients
}

\author{
Bhawana Wagle ${ }^{1}$, Yogesh Regmi \\ ${ }^{1}$ Head of Department, BP Koirala Memorial Cancer Hospital, ${ }^{2}$ Registrar, Department of Anaesthesia
}

\begin{abstract}
BACKGROUND : This is a prospective randomized, double blind study to determine the doses of rocuronium that would give $90 \%$ and $95 \%$ probabilities of successful tracheal intubation within 60 s after administration. This study evaluated intubating conditions and duration of action of $0.4 \mathrm{mg}, 0.8 \mathrm{mg}$ and $1.2 \mathrm{mg}$ of rocuronium, administered intravenously in patients undergoing elective surgical procedures. Goal in this study is to define doses level of rocuronium that would provide optimal relaxation for tracheal intubation in patients in whom succinylcholine was relatively contraindicated.

METHODS: Sixty patients both male and female, ASA I \& II, age between 18-60 years, with BMI of less that 30 who were planned for elective surgical procedures were randomized into three groups. Group A received $0.4 \mathrm{mg}$ $(n=20)$, Group B received $0.8 \mathrm{mg}(\mathrm{n}=20)$ and Group $C$ received $1.2 \mathrm{mg}(\mathrm{n}=20)$ of rocuronium. At 60 seconds after injection of the rocuronium, laryngoscopy was initiated, with the goal being endotracheal tube passed through the patient's vocal cords and the cuff inflated within the trachea in 20s. Intubating conditions was graded excellent, good or poor according to Cooper scoring system criteria. When the patient lost consciousness, train-of-four (TOF) stimulation (at $2 \mathrm{~Hz}$ and repeated every 12s) were recorded. Immediately after tracheal intubation and every 5 min thereafter the investigator counted the number of tactile TOF responses. The duration of action of rocuronium was defined as the time from the end of injection of rocuronium until reappearance of first tactile response to TOF stimulation.

RESULTS: There were twelve patients in the $0.4 \mathrm{mg} / \mathrm{kg}$ rocuronium group, two in the $0.8 \mathrm{mg} / \mathrm{kg}$ group, and one in the $1.2 \mathrm{mg} / \mathrm{kg}$ rocuronium group with an unacceptable intubation grade caused by sustained coughing at intubation. The D90 and D95 doses were $0.83(0.59-1.03)$ and $1.04(0.76-1.36) \mathrm{mg} / \mathrm{kg}$, respectively. Estimated time until first tactile train-of-four response after D50 and D95 doses were $43 \mathrm{~min}$ and $52 \mathrm{~min}$, respectively.

CONCLUSION: After induction with pethedine and sodium thiopentone, rocuronium in a dose of $0.8 \mathrm{mg} / \mathrm{kg}$ produces equivalent intubating conditions as that of $1.2 \mathrm{mg} / \mathrm{kg}$ after 60 seconds of administration.
\end{abstract}

Keywords: Anesthesia, neuromuscular blocking drug, neuromuscular function monitoring, rocuronium.

\section{INTRODUCTION}

Laryngoscopy and endotracheal intubation is one of the most important tasks to be accomplished during administration of general anesthesia. Performing rapid sequence induction, usually a muscle relaxant that facilitates intubation within shortest possible time after its administration is preferred. This necessitates the use of an induction agent and rapidly acting neuromuscular blocking agent (usually succinylcholine) given in rapid succession. The caring anesthesiologist is confronted with potential and dreaded complication of succinylcholine like hyperkalemia, malignant hyperthermia and many others.1, 2, 3 .

Rocuronium is a new non-depolarizing muscle relaxant with a rapid onset profile similar to succinylcholine but devoid of those side effects, so this is increasingly becoming popular among the anesthesiologists. Rocuronium is a monoquaternary aminosteroid, but it is much less potent, with an ED95 (the dose required to produce 95\% depression of the twitch response) of $0.3 \mathrm{mg} / \mathrm{kg}$. This lack of potency is

Correspondence

Dr. Bhawana Wagle, Department of Anaesthesia, B. P. Koirala Memorial Cancer Hospital Bharatpur, Chitwan, Email: bit2wagle@yahoo.com 
thought to be an important factor in determining onset of neuromuscular blockade. It acts by competing for nicotinic receptors at the motor end plate. Acetylcholinesterase inhibitors, such as neostigmine and edrophonium antagonize this action. ${ }^{4}$

The liver primarily eliminates Rocuronium with a small fraction $(\approx 10 \%)$ excreted in the urine. Its putative metabolite 17-desacetylrocuronium does not accumulate in significant quantities. In patients with liver disease (cirrhosis), the volume of distribution of rocuronium is increased for its clearance may be delayed causing prolonging the duration of action. So, in patients with hepatic disease dosing should be conservative and guided by careful monitoring of the neuromuscular function. Duration of action of single and repeated dose is not affected in-patients with renal failure. 5 The ED95 dose is $0.3-0.4 \mathrm{mg} / \mathrm{kg}$. Intubation dose is 0.45 $-0.6 \mathrm{mg} / \mathrm{kg}$. Maintenance dose is $0.15 \mathrm{mg} / \mathrm{kg}$. For faster intubating conditions higher doses of ED95 are employed. At higher doses, duration of action is prolonged. Especially in elderly prolonged duration of action is observed. Reports quote of slight to moderate increase in heart rate, either due to pain on injection or week vagolytic effect. The heart rate increases in between $10-25 \%$ at higher doses, while the heart rate increase is negligible at doses of $0.6 \mathrm{mg} / \mathrm{kg} .{ }^{5}$

This study was designed to determine the doses of rocuronium that would give $90 \%$ and $95 \%$ probabilities of successful tracheal intubation within $60 \mathrm{~s}$ after rocuronium administration. To compare intubating scores with different doses of rocuronium using the following criteria namely: 1. Ease of laryngoscopy, 2. Vocal cord position, 3. Vocal cord movement, 4. Airway reaction, 5. Movement of limbs to estimate the duration of muscle relaxing action of rocuronium with the different doses given intravenously in a dose of $0.4,0.8$, and $1.2 \mathrm{mg} / \mathrm{kg}$.

\section{METHODOLOGY}

Institutional ethical review committee approval was taken for the study. From February to June 2017, Patients were randomized in 3 groups in a consecutive prospective manner after they signed the informed consent from. The study was prospective, randomized, double blind type.

Altogether, 60 adult patients of both sexes who were scheduled for elective surgical procedures, meeting the criteria ( the patients of ASA physical status I-II, Age 18-60 years and the patients with no anticipated difficulty in mask ventilation or tracheal intubation) and not having any of the exclusion criteria( Patients having gastro esophageal reflux, weighing more than $30 \%$ of ideal BMI, suffering from neuromuscular disease and undergoing treatment with drugs known to interfere with neuromuscular transmission. ) were taken. Group A received $0.4 \mathrm{mg}(\mathrm{n}=20)$, Group B received $0.8 \mathrm{mg}(\mathrm{n}=20)$ and Group $C$ received $1.2 \mathrm{mg}$ $(\mathrm{n}=20)$ of rocuronium.

Each patients were premeditated with diazepam ( $5 \mathrm{mg}$ for less than $50 \mathrm{~kg}, 10 \mathrm{mg}$ for more than $50 \mathrm{~kg}$ ) orally the night before surgery. In the operating room appropriate monitoring (electrocardiogram, pulse oximetry and blood pressure cuff for NIBP) was done. Patient was then premedicated with intravenous midazolam $0.02-0.04-\mathrm{mg} / \mathrm{kg}$ $15 \mathrm{~min}$ prior induction and Pethidine, $0.5 \mathrm{mg} / \mathrm{kg}$, at the start of the pre-oxygenation procedure. Sodium thiopentone, $5 \mathrm{mg} / \mathrm{kg}$, was given to induce anesthesia. After the patient loses consciousness, intravenous rocuronium in a dose of 0.4, 0.8 or $1.2 \mathrm{mg} / \mathrm{kg}$ (for groups A,B,C), diluted in normal saline to a total volume of $10 \mathrm{ml}$ was administered. The dose each patient received was decided in a random basis by the selection of an unmarked envelope containing details of the dose. Twenty patients received each dose of rocuronium.

At $60 \mathrm{~s}$. after injection of the rocuronium, laryngoscopy was initiated, with the goal being to have the endotracheal tube passed through the patient's vocal cords and the cuff inflated within the following $20 \mathrm{sec}$. If the endotracheal tube cannot be passed successfully within $30 \mathrm{sec}$, i.e., $90 \mathrm{sec}$ after rocuronium, it was recorded as a case of failed intubation. All intubations were performed by the investigators and the intubating conditions was graded excellent, good or poor according to following criteria:

Table 1: Grading Criteria for intubating condition (Cooper Scoring System)

\begin{tabular}{|l|l|l|l|}
\hline \multicolumn{1}{|c|}{ Criteria } & \multicolumn{1}{|c|}{$\begin{array}{c}\text { Excellent } \\
\text { 3 Points }\end{array}$} & \multicolumn{1}{|c|}{$\begin{array}{c}\text { Good } \\
\text { 2 Points }\end{array}$} & \multicolumn{1}{c|}{$\begin{array}{c}\text { Poor } \\
\text { 1 Points }\end{array}$} \\
\hline $\begin{array}{l}\text { Ease of laryn- } \\
\text { goscopy }\end{array}$ & Jaw relaxed & Jaw resistant & Jaw tight \\
\hline $\begin{array}{l}\text { Vocal cord } \\
\text { position }\end{array}$ & Abducted & Intermediate & Adduction \\
\hline $\begin{array}{l}\text { Vocal cord } \\
\text { movement }\end{array}$ & None & Moving & Closing \\
\hline $\begin{array}{l}\text { Airway reac- } \\
\text { tion }\end{array}$ & None & Transient & $\begin{array}{l}\text { Sustain }>\text { sec- } \\
\text { onds }\end{array}$ \\
\hline $\begin{array}{l}\text { Movement of } \\
\text { limbs }\end{array}$ & None & Slight & Vigorous \\
\hline
\end{tabular}


The investigator performing the intubation and assessing the conditions was blinded to the dose of rocuronium administered. After tracheal intubation, anesthesia was maintained with halothane, oxygen, top up doses of rocuronium $0.1 \mathrm{mg} / \mathrm{kg}$ and pethedine boluses as required. Patient was kept on mechanical ventilation.

To monitor relaxation, before induction of anesthesia, surface electrodes were placed over the ulnar nerve at the wrist. After the patient lost consciousness, train-offour (TOF) stimulation (at $2 \mathrm{~Hz}$ and repeated every 12s) were recorded immediately after tracheal intubation and every 5 min thereafter to count the number of tactile TOF responses. The duration of action of rocuronium was defined as the time from the end of injection of rocuronium until reappearance of first tactile response to TOF stimulation.

The data were analyzed using SPSS software. ANOVA, Kruskal Wallis test, Chi square test were used for analysis of data.

\section{RESULTS}

There were no significant differences in terms age, sex, weight, and ASA status among groups.

Intubating condition scoring in points :

Table 2: Intubating condition scoring in points

\begin{tabular}{|c|c|c|c|c|c|c|}
\hline Study groups & $\begin{array}{l}\text { Ease of } \\
\text { Laryngoscopy }\end{array}$ & $\begin{array}{l}\text { Vocal cord } \\
\text { position }\end{array}$ & $\begin{array}{l}\text { Vocal cord } \\
\text { movement }\end{array}$ & $\begin{array}{l}\text { Airway } \\
\text { reaction }\end{array}$ & $\begin{array}{l}\text { Movement of } \\
\text { limbs }\end{array}$ & $\begin{array}{l}\text { Total score in } \\
\text { points }\end{array}$ \\
\hline Group A(0.4mg) & 3 & 3 & 3 & 2 & 2.5 & 13.5 \\
\hline Group B (0.8mg) & 3 & 3 & 3 & 3 & 3 & 15 \\
\hline Group C (1.2mg) & 3 & 3 & 3 & 3 & 3 & 15 \\
\hline Group A \& B & \multicolumn{6}{|l|}{$\mathrm{p}<0.0001^{*}$} \\
\hline Group A \& C & \multicolumn{6}{|l|}{$\mathrm{p}<0.0001^{*}$} \\
\hline Group. B \& C & \multicolumn{6}{|c|}{$\mathrm{p}=0.95$} \\
\hline Group. A,B \& C & \multicolumn{6}{|l|}{$\mathrm{p}<0.0001^{*}$} \\
\hline
\end{tabular}

Values are in median.

Group A patients had an intubation score ranging from 12 to 15 points. Patient's in-group B had an intubation score within a range of 13 to 15 points. Patient's in-group $\mathrm{C}$ had a intubation score ranging from 14 to 15 points.

Table 3: Individual Criteria of intubating condition:

\begin{tabular}{|c|c|c|c|c|c|c|}
\hline Indicators & $\begin{array}{c}\text { Ease of } \\
\text { Laryngoscopy }\end{array}$ & $\begin{array}{l}\text { Vocal cord } \\
\text { position }\end{array}$ & $\begin{array}{l}\text { Vocal cord } \\
\text { Movement }\end{array}$ & $\begin{array}{c}\text { Airway reac- } \\
\text { tion }\end{array}$ & $\begin{array}{c}\text { Movement of } \\
\text { limbs }\end{array}$ & Total \\
\hline $\begin{array}{c}\text { Group A: } \\
\text { Mean } \\
\text { Median } \\
\text { Mode } \\
\pm \text { SD }\end{array}$ & $\begin{array}{l}3 \\
3 \\
3 \\
0\end{array}$ & $\begin{array}{c}2.8 \\
3 \\
3 \\
0.41 \\
\end{array}$ & $\begin{array}{c}2.75 \\
3 \\
3 \\
0.44 \\
\end{array}$ & $\begin{array}{c}2.40 \\
2 \\
2 \\
0.50 \\
\end{array}$ & $\begin{array}{c}2.5 \\
2.5 \\
2 \\
0.51 \\
\end{array}$ & $\begin{array}{c}13.45 \\
13.50 \\
14 \\
0.75 \\
\end{array}$ \\
\hline $\begin{array}{c}\text { Group B: } \\
\text { Mean } \\
\text { Median } \\
\text { Mode } \\
\pm \text { SD }\end{array}$ & $\begin{array}{l}3 \\
3 \\
3 \\
0\end{array}$ & $\begin{array}{c}2.95 \\
3 \\
3 \\
0.22 \\
\end{array}$ & $\begin{array}{c}2.95 \\
3 \\
3 \\
0.22 \\
\end{array}$ & $\begin{array}{l}3 \\
3 \\
3 \\
0\end{array}$ & $\begin{array}{c}2.9 \\
3 \\
3 \\
0.30 \\
\end{array}$ & $\begin{array}{c}14.85 \\
15 \\
15 \\
0.48 \\
\end{array}$ \\
\hline $\begin{array}{l}\text { Group C: } \\
\text { Mean } \\
\text { Median } \\
\text { Mode } \\
\pm \text { SD }\end{array}$ & $\begin{array}{l}3 \\
3 \\
3 \\
0\end{array}$ & $\begin{array}{l}3 \\
3 \\
3 \\
0\end{array}$ & $\begin{array}{l}3 \\
3 \\
3 \\
0\end{array}$ & $\begin{array}{l}3 \\
3 \\
3 \\
0\end{array}$ & $\begin{array}{l}2.9 \\
3 \\
3 \\
0.30\end{array}$ & $\begin{array}{l}14.90 \\
15 \\
15 \\
0.30\end{array}$ \\
\hline
\end{tabular}

\section{0}


Table 4: Individual Criteria of intubating condition

\begin{tabular}{|c|c|c|c|c|}
\hline \multirow{2}{*}{ Individual criteria } & Group A (0.4mg) & Group B (0.8mg) & Group C (1.2mg) & \multirow{2}{*}{$p$ value } \\
\hline & $\mathrm{n}=\mathbf{2 0}$ & $\mathrm{n}=\mathbf{2 0}$ & $\mathrm{n}=\mathbf{2 0}$ & \\
\hline Ease of Laryngoscopy excellent & $20(100 \%)$ & $20(100 \%)$ & $20(100 \%)$ & - \\
\hline Vocal cord position excellent & $16(80 \%)$ & $19(95 \%)$ & $20(100 \%)$ & 0.059 \\
\hline Vocal cord position good & $4(20 \%)$ & $1(5 \%)$ & - & 0.059 \\
\hline Vocal cord Movement excellent & $15(75 \%)$ & 19(95\%) & $20(100 \%)$ & $0.021^{*}$ \\
\hline Vocal cord Movement good & $5(25 \%)$ & $1(5 \%)$ & & $0.021^{\star}$ \\
\hline Airway reaction excellent & $8(40 \%)$ & $20(100 \%)$ & $20(100 \%)$ & $<0.0001^{\star}$ \\
\hline Airway reaction good & $12(60 \%)$ & - & - & $<0.0001^{\star}$ \\
\hline Movement of limbs excellent & $10(50 \%)$ & $18(90 \%)$ & $18(90 \%)$ & $0.003^{*}$ \\
\hline Movement of limbs good & $10(50 \%)$ & $2(10 \%)$ & $2(10 \%)$ & $0.003^{*}$ \\
\hline
\end{tabular}

* Statistically significant

Table 5: Time course and duration of action

\begin{tabular}{|l|l|l|l|l|l|}
\hline Time course and action & Group A (0.4mg) & Group B (0.8mg) & Group C (1.2 mg) & p value & p value between \\
\hline $\begin{array}{l}\text { Duration of laryngos- } \\
\text { copy (sec) }\end{array}$ & $14.50 \pm 3.72$ & $13.90 \pm 3.69$ & $14 \pm 3.38$ & 0.84 & $\begin{array}{l}\text { Group A \& B }=0.59 \\
\text { Group A \& C }=0.65 \\
\text { Group B \& C }=0.89 \\
\text { Group A, B \& C }=0.84\end{array}$ \\
\hline $\begin{array}{l}\text { Clinical duration of } \\
\text { action (min) }\end{array}$ & $18.85 \pm 4.46$ & $43.6 \pm 6.13$ & $52.6 \pm 11.06$ & $<0.0001$ & $\begin{array}{l}\text { Group A \& B }=0.07 \\
\text { Group A \& C }=0.37 \\
\text { Group B \& C }=0.44 \\
\text { Group A, B \& C }=0.21\end{array}$ \\
\hline
\end{tabular}

Kruskal Wallis test and ANOVA were used.

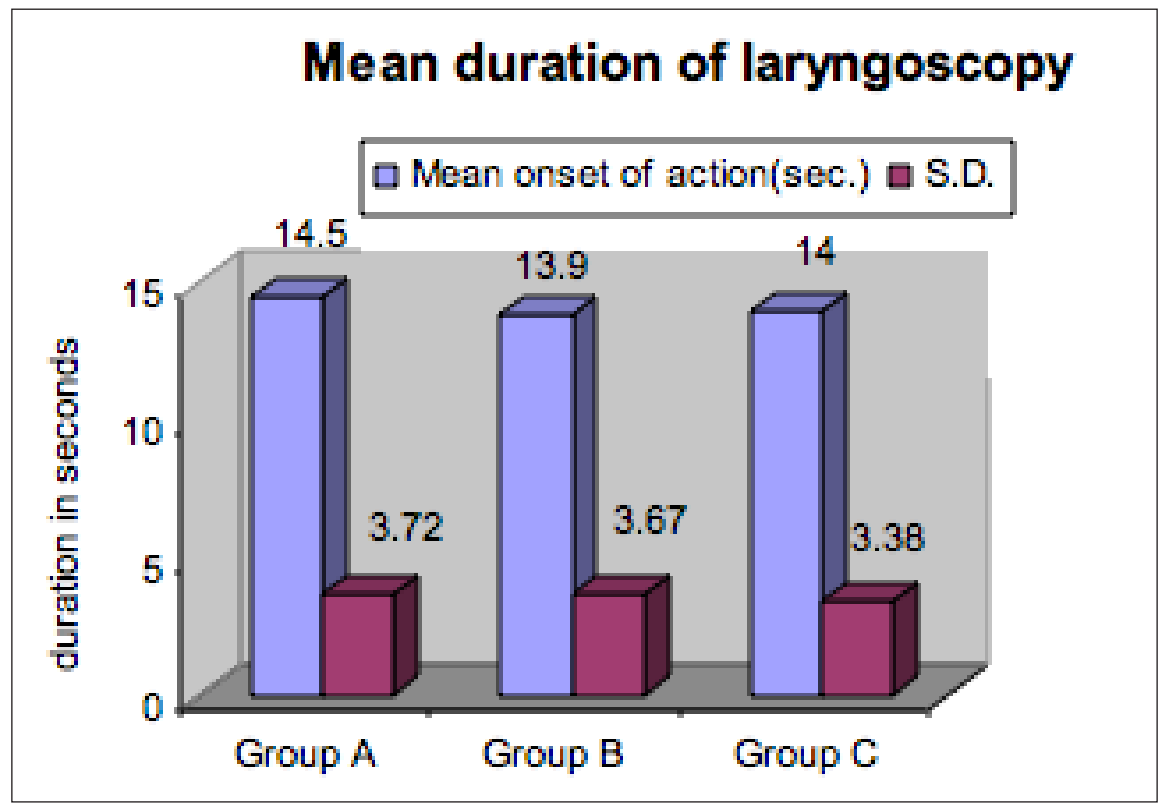

Figure 1 : Bar diagram showing mean duration of laryngoscopy 
Mean duration of laryngoscopy of the patient was $14.50 \pm 3.72 \mathrm{sec}$ in group-A, $13.90 \pm 3.69 \mathrm{sec}$ in group-B and respectively in $14 \pm 3.38 \mathrm{sec}$ in group-C. As the p value is $>0.05$, it is not statistically significant and three groups are comparable statistically in duration of larygoscopy.

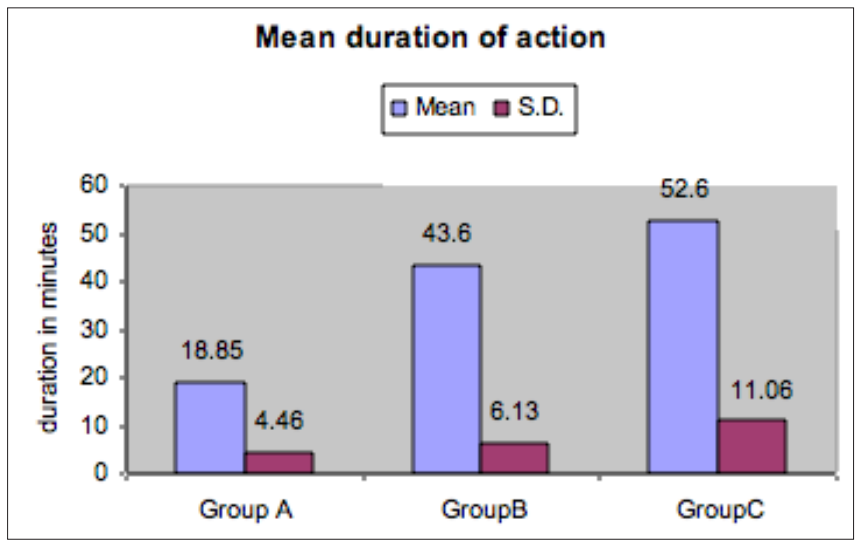

Figure 2: Bar diagram showing mean duration of action

Mean duration of action of the patient was $18.85 \pm 4.46 \mathrm{~min}$ in group-A, $43.6 \pm 6.13 \mathrm{~min}$ in group-B and respectively in $52.6 \pm 11.06 \mathrm{~min}$ in group-C. As $\mathrm{p}$ value is $<0.05$ therefore three groups are comparable statistically with difference in mean duration of action between the groups.

\section{DISCUSSION}

Rapid sequence oro-tracheal intubation is usually performed after induction in emergency cases with the application of cricoid pressure, to prevent the aspiration of gastric contents into the trachea. Recent advances and newer nondepolarizing muscle relaxants have nowtaken up theposition of succinylcholine by offering better advantages and are the alternatives where succinylcholine use is contraindicated during rapid sequence induction and intubation. Goal in this study is to define low doses of rocuronium that would provide a high probability of producing perfect conditions for tracheal intubation in patients in whom succinylcholine was relatively contraindicated.

This study differs from previous investigations of rapid tracheal intubation facilitated by rocuronium using traditional methods because none of them attempted to define a dose-response relationship. 2,6,7,8 In previous studies, the incidence of successful intubation at different doses of rocuronium (ranging for 0.6 to $1.2 \mathrm{mg} / \mathrm{kg}$ ) was reported, but a probability of success was never defined. Defining a dose of a drug in terms of probability of therapeutic success has several advantages over the more traditional approaches. First, it allows clinical decisionmaking about choice of dose, which can incorporate weighing the consequences of that choice. With the approach used by Kierkegaard-Nielsen and Caldwell et al 11 as in this study, the importance of having a high probability of successful intubation can be weighed against the consequence, which is longer duration of action. Second, use of this approach allows rapid determination of drug doses required to achieve specific therapeutic goals. The D95 dose of rocuronium that we defined $(1.04 \mathrm{mg} / \mathrm{kg})$ is similar to the doses, $0.9-1.0 \mathrm{mg} / \mathrm{kg}$, which have already been recommended in other studies. 7, 8 However, the process of determining that doses on the order of $1.0 \mathrm{mg} / \mathrm{kg}$ are necessary to facilitate rapid tracheal intubation has been one of evolution, over a period of years, incorporating the results from several different studies. 2,6,7,9

Third, using probability allows for true comparative studies of drugs or factors influencing their action. For example, doses of different drugs that are truly equipotent for a given response can be determined. If the dose of succinylcholine that provides $95 \%$ probability of successful intubation was defined, then this would be the dose that was truly equipotent with the D95 $(1.04 \mathrm{mg} / \mathrm{kg})$ of rocuronium. In a similar manner, the influence of different anesthetic regimens on the efficacy of rocuronium could be studied. For example, the question of whether different anesthetic induction drugs alter the D95 dose could be asked and easily answered.

Rocuronium at a dose of $0.6 \mathrm{mg} / \mathrm{kg}$ was found inadequate for pediatric intubation while that of $0.9 \mathrm{mg} / \mathrm{kg}$ was adequate to provide similar intubating conditions as that of $1.5 \mathrm{mg} / \mathrm{kg} .10$ The advantage of rocuronium over other nondepolarizing muscle relaxants is that of early intubating conditions due to its low potency and this property makes it an ideal replacement for succinylcholine.10 The use of rocuronium as a substitute for succinylcholine in pediatric surgery was studied at different doses by Mazurek and colleagues and recommended rocuronium $1.2 \mathrm{mg} / \mathrm{kg}$ for emergency rapid intubations. 12 Minimum dose of $0.6 \mathrm{mg} /$ $\mathrm{kg}$ is needed to achieve adequate intubating condition in children with ASA grade II \& I.13 At a dose of $0.6 \mathrm{mg} / \mathrm{kg}$, optimal intubating conditions are obtained at 1 minute in children.14 The mild vagolytic action produced by rocuronium is surely beneficial in this population since their cardiac output depends on the heart rate. 
Conditions for tracheal intubation were rated similar to the scoring system adapted by Tom Heier and James E.Caldwell from Good clinical research practice (GCRP) in pharmacodynamics studies of neuromuscular blocking agents. 15, 16 In this study it was opted to use the same intubating criteria since it was simple, easy and feasible in our hospital setting, where sophisticated monitoring techniques like EMG and accelerography were not available. The intubation scores were graded on a 3 point scale, comprising of 5 criteria's. The criteria are included in the study-included ease of laryngoscopy, vocal cord position, vocal cord movement, airway reaction and movement of limbs during laryngoscopy and intubation. The scores were given in points, as 3 points for excellent condition, 2 points for good and 1 point for poor intubating conditions during laryngoscopy and intubation. During analysis of the intubating conditions both the total score of all the 5 criteria's as well as the individual criteria's were assessed individually.

In this study it was aimed to achieve tracheal intubation at $60 \mathrm{~s}$ after rocuronium injection. It was chosen $60 \mathrm{~s}$ because this is within the time range (60-90s) recommended for rapid tracheal intubation 17 , and the range (45-75s) used in previous studies. 5,6,7,8 There were no use of cricoid pressure in this study, and in this way this technique differs from rapid sequence intubation for prevention of pulmonary aspiration of gastric contents. Cricoid pressure improves the view of the larynx during laryngoscopy, and it is possible that intubating conditions could have been enhanced by the use of cricoid pressure. However, absence of cricoid pressure does not have significant influenced on results. In the patients in whom intubation was judged unacceptable it was not because of poor visualization of the larynx, but rather because of unable to open the patient's mouth, the vocal cords remained closed during attempted intubation, or there was sustained coughing after placement of the endotracheal tube. Cricoid pressure would not have changed the outcome in these situations.

The choice and doses of the induction agents used also influences the onset of neuromuscular blockade and the ease of intubation. Propofol was used for induction in the studies performed by Andrews JI et al,and Woolf RL et al $.18,19$ The role of induction agent on the intubating conditions has been widely published stressing the need to use a good induction agent when rapid oro-tracheal intubation is contemplated taking into account of other factors to be considered. Ketamine has been suggested as an alternative induction agent to thiopentone used in our study. Ketamine along with rocuronium $0.6 \mathrm{mg} / \mathrm{kg}$ was found to be a suitable alternative in emergency caesarian section.20 Etomidate when used for induction pior to rocuronium administration cannot be recommended for rapid sequence oro-tracheal intubation.21 whereas propofol when combined with rocuronium provides better intubating conditions than thiopentone used in this study.22 Propofol and rocuronium were used so frequently by a third of the respondent in a questionnaire. Tryba et al, confirmed that the administration of thiopentone as induction agent prior to the administration of rocuronium, as in this study, was found to give better intubation scores compared to administration of muscle relaxant followed by thiopentone.23 The usage of opioids as an integral part of induction intubation sequence as in this study has been supported by a study done by Sparr HJ et al 3, where the conclusion of role of opioid's in the provision of effective intubating conditions has been proven.

Increased probability of successful intubation using larger rocuronium doses carries with it the consequence of a longer duration of action as in the study done by Kirkegaard-Nielsen and Caldwell et al.24 Illustrates same relationship as in this study found between rocuronium dose and duration of action. Duration of action is defined as the time to return of the first TOF response, as this is the criterion most accessible to the clinician and represents the earliest point at which induced reversal with an anticholinesterase is appropriate. In this study results show that a D90 dose of rocuronium $(0.83 \mathrm{mg} / \mathrm{kg})$ has a mean estimated duration of $43 \mathrm{~min}$, with the 95th percentile for this estimate approximately $58 \mathrm{~min}$. In comparison, a D95 dose of rocuronium $(1.04 \mathrm{mg} / \mathrm{kg})$ has a mean estimated duration of $52 \mathrm{~min}$, with the 95 th percentile for this estimate being almost $70 \mathrm{~min}$. Thus, in an individual patient, the possibility of long duration of action must be balanced against the need for rapid tracheal intubation. However, because the duration of action of rocuronium is dependent on the type and dose of drugs (particularly volatile agents) used to maintain anesthesia, should not be interpreted as accurately predicting duration of action in conditions other than those in this study.

The drugs used to induce anesthesia significantly influence conditions for trachealintubation. Adjustment of opioid dose or the use of increased doses of propofol or etomidate may 
permit a high probability of successful tracheal intubation with smaller doses of rocuronium than suggested by our results.22 In contrast, the use of thiopental for anesthetic induction may require use of larger doses than we describe. 23 The "priming" and "timing" principles have been used to enhance intubation conditions with rocuronium9,15, but these techniques carry the risks of premature weakness 9, pain on injection 24, and precipitation in the intravenous tubing. 25 It would be possible to achieve perfect intubation conditions with smaller doses of rocuronium if larger doses of induction drugs have been used or had used propofol instead of thiopental . However, because we envisioned trauma victims as a group to which our results might have relevance, it was thought to use a "light" general anesthetic and to avoid techniques associated with greater risk of hypotension. Thus, this study is relying more on the effect of rocuronium and less on the central depression from anesthesia to facilitate intubation.

Another mechanism to improve the probability of achieving perfect conditions would be to delay the time of intubation from 60 to 90 seconds after the rocuronium administration. There is no clear consensus on the time interval that constitutes rapid tracheal intubation. In most recent studies, laryngoscopy has commenced between 45 and 60 seconds after the rocuronium administration. The priority attached to the rapidity of tracheal intubation is a clinical decision, individualized to each situation. It is expected that results in this study will add to the information available to the clinician and aid in their decision-making process.

All but one patient had four tactile TOF responses at the adductor pollicis muscle at the time of intubation, regardless of the intubating conditions. This finding is consistent with pharmacodynamics studies of rocuronium demonstrating a faster onset of neuromuscular block at the laryngeal muscles compared to the adductor pollicis. 30 This result further emphasizes that TOF responses at the adductor pollicis are not useful if one is attempting rapid tracheal intubation with rocuronium.

In conclusion, all these results only suggest that rocuronium in a dose of $0.8 \mathrm{mg} / \mathrm{kg}$ produces equivalent intubating conditions as that of $1.2 \mathrm{mg} / \mathrm{kg}$ after 60 seconds of muscle relaxant administration when used for rapid sequence orotracheal intubation.

With this study we can recommend rocuronium in a dose of $0.8 \mathrm{mg} / \mathrm{kg}$ produce equivalent intubating conditions as that of $1.2 \mathrm{mg} / \mathrm{kg}$ after 60 seconds of muscle relaxant administration when used for rapid sequence oro-tracheal intubation. Perfect intubation condition could be achieved with smaller dose of rocuronium if large doses induction drugs or had used fentanyl instead of pethidine and propofol instead of thiopentone.

Limitations of this studie is sample size was limited, the study was conducted only in the adults and not in pediatric patients, patient with Mallampatti class only $1 \& 2$ were selected. The results of intubation might be different in patients of classes. Only simplest forms of monitoring were used in this study. Other forms of monitoring like EMG could not be made to arrive to a better conclusion.

\section{REFERENCES}

1. Magorian T, Flannery KB, Miller RD. Comparison of rocuronium, succinylcholine, and vecuronium for rapid-sequence induction of anesthesia in adult patients. Anesthesiology 1993; 79 (5): 913-8.

2. Huizinga ACT, Vandenbrom RHG, Wierda JMKH, Hommes FDM, Hennis PJ. Intubating conditions and onset of neuromuscular block of rocuronium (Org 9426): A comparison with suxamethonium. Acta Anaesthesiol Scand 1992; 36 (5): 463-8.

3. Sparr HJ, Giesinger S, Ulmer H, Hollenstein-Zacke $\mathrm{M}$, Luger TJ. Influence of induction technique on intubating conditions after rocuronium in adults: Comparison with rapid-sequence induction using thiopentone and suxamethonium. Br J Anaesth 1996; 77 (3): 339-42.

4. McCourt KC, Salmela L, Mirakhur RK, Carroll M, Mäkinen M-T,Kansanaho M, KerrC, Roest GJ, Olkkola KT. Comparison of rocuronium and suxamethonium for use during rapid sequence induction of anaesthesia. Anaesthesia 1998; 53(2): 867-71.

5. Bartkowski RR, Witkowski TA, Azad S, Lessin J, Marr A. Rocuronium onset of action: A comparison with atracurium and vecuronium. Anesth Analg 1993; 77 (10): 5748 .

6. Crul JF, Vanbelleghem V, Buyse L, Heylen R, van Egmond J. Rocuronium with alfentanil and propofol allows intubation within 45 seconds. Eur J Anaesthesiol Suppl 1995; 11(9): 111-2. 
7. Patel N, Kamath N, Smith C E. Intubating conditions and neuromuscular block after divided dose mivacurium or single dose rocuronium. Can J Anaesth 1997; 44(1): 49-53.

8. Wright PMC, Caldwell JE, Miller RD. Onset and duration of rocuronium and succinylcholine at the adductor pollicis and laryngeal adductor muscles in anesthetized humans. Anesthesiology 1994; 81(9):1110-5.

9. Schmidt H, Wolf K. Comparison of succinylcholine with two doses of rocuronium using a new method of monitoring neuromuscular block at the laryngeal muscles by surface laryngeal electromyography. Br. J. Anaesth. 2000; 85 (10):251-255.

10. Cheng Ca, Aun CS, Gin T: Comparison of rocuronium and suxamethonium for rapid tracheal intubation in children Paediatr Anaesth 2002;12(2):140-5.

11. Huizinga AC,Vanderbrom RH, Weirda JM : Intubating conditions and onset of neuromuscular block of rocuronium(Org 9426); a comparison with suxamethonium. Acta Anaesthesiol Scand 1992 ; 36(5): 463-8.

12. Mazurek AJ, Rae B, Hann S : Rocuronium versus succinylcholine:Are they equally effective during rapid sequence induction of anesthesia. Anesth Analg 1998; 87(6): 1259-62.

13. Ross AK, Dear RB :Onset and recovery of neuromuscular blockade after two doses of rcuronium in children. J Clin Anesth 1998; 10(8):631-5.

14. Stoddart PA, Mather SJ: Onset of neuro-muscular blockade and intubating conditions one minute after the administration of rocuronium in children. Paediatr Anaesth 1998; 8(1): 37-40.

15. Heier T, Caldwell JE. Rapid Tracheal Intubation with Large-Dose Rocuronium: A Probability-Based ApproachAnesth Analg 2000; 90(1):175-9.

16. Viby-Mogensen J, Enbaek J, Eriksson LI: Good clinical research practice (GCRP) in pharmacodynamics studies of neuromuscular blocking agents.Acta Anaesthesiol Scand 1996; 40 (1):59-74.

17. Xue,Fu S, Tong, Si Y.; Liao, Xu; Liu, Jian H.; An, Gang; Luo, Lai K. Dose-Response and Time Course of Effect of Rocuronium in Male and Female Anesthetized Patients. Anesth Analg 1997; 85(3):667-71.

18. Andrews JI, Kumar N, van den Brom RH .A Large simple randomized trail of rocuronium versus succinylcholine in rapid sequence induction of anaesthesia alone with propofol. Acta Anethesiol Scand 1999; 43(1): 4-8.

19. Woolf RL,Crawford MW, Choo SM: Dose response of rocuronium bromide in children anesthetized with propofol: A comparison with succinylcholine Anesthesiology 1997; 87(6):1368-72.

20. Baraka SS, Sayyid SS, Assaf BA: Thiopentalrocuronium versus ketamine- rocuronium for rapidsequence intubation in parturients undergoing caesarian section. Anesth Analg 1997;84(5):1104-7.

21. Skinner HJ, Biswas A, Maharjan RP: Evaluation of intubating conditions with rocuronium and either propofol or etomidate for rapid sequence induction. Anaesthesia 1998: 53(7): 702-6.

22. Dobson AP, McCluskey A, Meakin G : Effective time to satisfactory intubation after administration of rocuronium in adults. Comparison of propofol and thiopentone for rapid -sequence induction of anaesthesia. Anaesthesia 1999;54(2):172-6.

23. Tryba M, Zorn A, Thole $\mathrm{H}$ et al: Rapid sequence orotracheal intubation with rocuronium: a randomized doubleblind comparision with suxamethonium- a preliminary communication. Eur J Anaesthesiol Suppl 1994; 9(4): 44-8.

24. Kirkegaard-Nielsen, Hans, Caldwell, James E., Berry, Peter D. Rapid Tracheal Intubation with Rocuronium: A Probability Approach to Determining Dose. ASA, San Diego, California 1997; 94143-0648.

25. M. Leuwer, J. Motsch, U. Schledt, A. Krupp. Doseresponse, time course of action and recovery of Org 9426 (rocuronium) in infants during halothane anaesthesia. Br. J. Anaesth. 1994; 73 (6):716. 